\title{
AVALIAÇÃO: O QUE O ALUNO ESPERA DO PROFESSOR?*
}

Antônio Wilson Pagotti** Sueli Assis de Godoy Pagotti***

\section{RESUMO}

Uma das diversas etapas da avaliação institucional é a avaliação que o aluno faz do docente. A instituição ao analisar os dados pensa no "professor ideal". Mas será este mesmo professor idealizado pelo aluno? O presente estudo procura investigar as expectativas do aluno sobre o professor. $\mathrm{O}$ instrumento para o estudo foi uma pergunta “o que você espera de um bom professor?", feita a 432 alunos universitários. As respostas foram organizadas em 20 categorias e reorganizadas em três domínios: domínio de conhecimentos; domínio de sala de aula (didático pedagógico) e domínio da relação sociopsicológica. Os dados mostram o distanciamento entre as expectativas e a realidade vivida.

Palavras-chave: expectativas do estudante, avaliação docente e professor ideal.

Em 1995, Paulo Freire, falando sobre as expectativas de professores e alunos no processo educacional, destacou:

não é possível que os dois desconheçam suas expectativas e responsabilidades. Por isso, eu me bato para que o estudo das responsabilidades e das expectativas vire quase conteúdo... todos os professores numa administração democrática estariam aptos a discutir suas responsabilidades e suas expectativas (p. 6).

\footnotetext{
* Artigo recebido em 9/3/2004 e aprovado em 6/8/2004.

** Mestre em Psicologia Social pela PUC-SP e doutor em Psicologia da Educação pela PUC-SP. E-mail: apagotti@terra.com.br

*** Mestre e doutora em Psicologia da Educação pela PUC-SP. E-mail: sgpagotti@terra.com.br
} 
O presente trabalho pretende contribuir nesse sentido. Acreditamos que a educação dialógica, participante, permite a reflexão analítica e a transformação nas relações de ensino e aprendizagem.

$\mathrm{O}$ ponto de partida para o estudo das expectativas de docente e discentes é avaliá-las, o que dará a base para a reflexão. O que o professor avalia no aluno? Quando esta pergunta é feita ao aluno, ele tende a destacar em sua resposta o desempenho acadêmico, salientando que o professor avalia-o através de provas e exames. Mas, e se perguntarmos o que o aluno avalia no professor? Se levarmos em consideração a maioria dos modelos de avaliação institucional praticados, nos quais o aluno avalia o professor levando em conta as notas que ele obtém na disciplina ministrada por ele, será obtido um conjunto de respostas pouco esclarecedor e, em síntese, chegaremos à mesma percepção de Demo (2000): a tendência é o professor ser visto como herói ou bode expiatório, uma vez que o próprio processo de ensino e aprendizagem não é revelador das etapas de desenvolvimento do aluno, e os procedimentos de avaliação estão calcados em modelos reprodutivistas.

Assim, avaliar o professor deve exigir uma reflexão mais abrangente e incorporar o contexto educacional, considerando que o panorama da educação no Brasil é caótico. Dados do Inep mostram que no ensino médio aproximadamente $20 \%$ dos alunos abandonam a escola e, entre os 6.335.050 ingressantes em 2002, somente 1.884.874 concluíram o curso em período regular. Esse "filtro" poderia indicar exigência e qualificação, porém, o Enem (exame nacional do ensino médio) que, no ano 2003, avaliou aproximadamente um milhão e novecentos mil alunos e tem como objetivo verificar as competências, mais do que a capacidade de acumular informações, mostra que não há "filtro" de qualificação. Os resultados, a partir de 1998, indicam que a principal dificuldade dos estudantes é construir argumentações consistentes, e, na maioria das competências avaliadas, o desempenho tem sido insuficiente ou regular.

No ano de 2002, conforme o Inep (2003), entre os estudantes concluintes do ensino médio que participaram do exame, $74 \%$ foram classificados como insuficientes, tendo o desempenho pontuado entre $0 \%$ e $40 \%$ de acertos; $23,5 \%$ dos alunos obtiveram notas entre $40 \%$ e $70 \%$, sendo classificados entre regular e bom, e apenas $2,5 \%$ dos alunos classificados entre $70 \%$ e $100 \%$ de acertos.

Se, de um lado, o desempenho dos alunos é fraco, de outro, os professores devem estar mal preparados. Reclamações não faltam, como 
destacam Nogueira et alli (2003). Em Recife, 88\% dos professores queixam-se de algum problema de saúde relacionado à profissão; $80 \%$, reclamam por terem que trabalhar em pé; $69 \%$ pela falta de programa de capacitação. Essas carências interferem profundamente na relação ensino-aprendizagem e geram conseqüências na avaliação do docente.

Mas há formas de trabalhar na solução desses problemas e, mais particularmente, nas expectativas docente e discente? Freire (1995, p. 2) destaca:

eu não posso satisfazer a expectativa do educando se não satisfizer a minha expectativa de professor, de educador. A expectativa do educando seria, por exemplo, a de aprender, que corresponde a minha de ensinar... eu não posso ser bom professor senão me envolvo com o aprendizado do aluno, eu não posso ajudá-lo a aprender... Do outro lado da expectativa aparece a responsabilidade. Quando penso na expectativa de ensinar corretamente, de ensinar bem, eu assumo a responsabilidade de fazer isso. A responsabilidade docente está no sentido de tornar efetiva a expectativa docente, a responsabilidade discente está em tornar efetiva a expectativa discente... se ele não aprender tem alguma coisa errada, que pode estar nele, no processo de aprender e no processo de ensinar do educador.

É nesse campo que se coloca a avaliação, e, de forma específica, "avaliar para educar", principalmente no tocante ao papel do professor. Sousa (1997) enfatiza que a avaliação que o professor faz define seus valores, sua visão de futuro e da sociedade que pretende construir com os alunos que está formando. Sousa (1999, p. 145), destaca ainda que a

avaliação do aluno em sala de aula tem por propósito promover o aperfeiçoamento do ensino que vem sendo oferecido. Avalia-se para identificar as necessidades e prioridades, situar o próprio professor e o aluno no percurso escolar.

De maneira ampla, pode-se dizer que educar implica na ação docente que procura contribuir para que o aluno busque sua autonomia intelectual e moral e atue produtivamente na sociedade. Nesse sentido, é necessário que o professor esteja atento às formas de pensar do aluno, à maneira como ele soluciona os problemas e participa das aulas. Só é possível uma boa avaliação de ensino-aprendizagem à medida que o 
professor acompanhe diretamente o desenvolvimento do aluno, dando a ele a oportunidade de se manifestar, questionar e opinar.

O ambiente democrático, coordenado pela autoridade do professor, propicia a construção adequada do conhecimento. Esse caminho implica, para o aluno, na compreensão de si e no relacionamento com o outro, cabendo ao professor verificar nos alunos as condições educacionais, acompanhar seu desempenho e a evolução escolar. Esta não é uma tarefa tranqüila, pois, como ressalta McDonald (1985), apud Luckesi (1998), o professor pode mostrar preconceitos de comportamento, preferindo o aluno bem comportado; preconceito de estética, julgando mais pela aparência do que pelo conteúdo e preconceito pelo cansaço, quando os resultados das avaliações são mais ou menos generosos se os exercícios são corrigidos no início ou no final da leitura. Pois o comportamento que o professor expressa é mediado pelo que ele pensa e espera dos alunos, o que envolve interesses, motivações, competências que ele atribui ao aluno e, em sentido recíproco, o aluno comporta-se mediatizando o que pensa e espera do professor.

Há ainda, como ressaltam Depresbitéris e Taurino (1997), o difícil percurso do educador para avaliar, pois avaliar é julgar. Assim, para julgar é necessário definir critérios e, para se ter critérios, é preciso levantar indicadores. Avaliar deve pressupor abrangência para abordar: o conhecimento já adquirido, a aplicação dos conhecimentos, o saber fazer (identificando as habilidades) e o saber ser (identificando as atitudes do aluno diante das situações-problema e na tomada de decisões).

Para Moreira (1998), o professor é obviamente o fator mais crítico na eficácia de qualquer programa objetivando a melhoria no ensino. É nesse contexto que a avaliação do docente feita pelo aluno tem destaque. Afinal, o aluno é o sujeito terminal da ação educativa docente e o conhecimento construído por ele é o reflexo de uma práxis.

Ao pensar-se a avaliação docente, deve-se ter não só o ponto de vista da instituição, mas principalmente dos próprios docentes. A avaliação do docente normalmente é feita pelo aluno, e isto tem um peso duplo que se revela, como aponta Perrenoud (2000), no exercício da educação e também na ligação afetiva, elementos de grande importância no ensinoaprendizagem. $\mathrm{O}$ aluno deve estar preparado para avaliar o professor; mais ainda, o aluno deve questionar-se sobre o seu próprio desempenho acadêmico, a importância da busca do conhecimento, os seus objetivos pessoais e o seu desenvolvimento educacional. 
Avaliando o professor, o aluno pode recuperar a sua própria história escolar e nisso se incluem as lembranças das aulas, o exercício da docência, a falta de clareza nas avaliações, a avaliação utilizada como mecanismo de controle punitivo.

Os resultados das opiniões dos alunos exigem do professor repensar sua prática de ensino avaliativa, uma vez que, comumente, ela é vista como elemento de repressão, que resulta de provas e notas, aprovação e reprovação. Em contrapartida, o aluno diante da situação repressora, tende a desenvolver estratégias de escape, na "cola" e nas justificativas.

Esses desvios nos objetivos educacionais estão descritos no estudo de Oliveira (2000) com estudantes de graduação do curso de Pedagogia, no trabalho sobre o tema "mitos e desafios da avaliação". Foi solicitado aos alunos que indicassem por escrito as imagens que formam quando se fala em avaliação no contexto educacional. Entre 42 imagens apresentadas, apenas duas $(4,8 \%)$ destacaram aspectos positivos: a primeira referia-se à coruja, justificada como "observação de todos os lados e sabedoria", enquanto a segunda referia-se à Dona Benta (personagem de Monteiro Lobato), dando uma dimensão afetiva à avaliação, para quem a criança é um ser total, único, que difere dos outros". As demais imagens $(95,2 \%)$ destacaram a avaliação pelos aspectos negativos, em vários níveis: gerando incerteza (pois a avaliação é uma "caixa de surpresas, não se sabe o que poderá acontecer"), desconfiança (a avaliação é como "camaleão, com a cabeça diz que sim com o rabinho diz que não"), incompetência ("plano econômico, procuram acertar e no final..."), a necessidade da esperteza do aluno ("pois ele tem que ser raposa, astuto para descobrir o que o professor irá avaliar"), perseguição ("caçador e caça, o professor armado, o aluno não escapa"), instabilidade ("casa velha, pode despencar a qualquer hora em cima de nós"), traição ("cobra, dá o bote quando menos se espera"), ameaça ("fantasma, dá medo, é misterioso e não conhecemos"), ditadura ("Hitler, dominador, mandão, não ouve o povo").

A representação social da avaliação, no estudo de Oliveira (2000), revela a forma de conhecimento presente no senso comum, expressa valores, conceitos, idéias e crenças compartilhadas. Essas representações orientam as condutas das pessoas e dos grupos e destaca uma visão negativa, persecutória. 
Porém, a avaliação não se faz sozinha. O professor é quem a planeja e aplica-a. O professor é quem a corrige e qualifica-a. Nesse sentido, a imagem da avaliação está intimamente relacionada ao professor e conseqüentemente interfere na relação ensino-aprendizagem.

Outro aspecto importante, além da imagem, é ter dados sobre como o aluno "vê" o professor. O estudo de Pearmann e McCann, apresentado em Murray (2000), avalia a atividade de ensino docente pela ótica dos alunos e com isto levanta os "hábitos desagradáveis do professor". Os autores solicitaram a 700 alunos, no primeiro dia de aula, que relacionassem as principais queixas sobre os professores. Os resultados mostram que o que mais desagrada os alunos são professores que não organizam e não planejam adequadamente as aulas, que tenham como estilo de ensino aulas monótonas, uso pobre dos recursos visuais e professores que dão provas sobre materiais não incluídos nos textos ou nas leituras. Esses dados mostram o que os alunos não gostam, porém, é importante verificar também o que os alunos esperam do professor.

Um ponto que se pretende enfatizar aqui é o campo da avaliação docente privilegiando as expectativas do aluno sobre o professor. Quando o aluno explicita suas expectativas em relação ao professor está também, de forma implícita, colocando as expectativas sobre a sua formação pessoal-educacional. Como o aluno é, durante todo o período letivo, observado e avaliado pelo professor, como processo da interação, o aluno também observa e avalia o professor. A avaliação do docente interfere na vida do aluno, pois o julgamento implica em aprovação ou reprovação, sucesso ou fracasso. Assim é importante saber, através da ótica de quem está sendo formalmente avaliado, o que esperar do professor, pois, como destaca Freire (1995, p. 2), "a responsabilidade do educador é trabalhar a responsabilidade do educando para que se supere, em comum, as dificuldades e compatibilizem as expectativas".

Nessa interação coloca-se o estudo de Murray (2000) que salienta que os professores esperam que os alunos sejam organizados, e estes esperam o mesmo dos professores.

Procurando levantar dados referentes às expectativas dos alunos sobre os professores, foi feita a 432 universitários, das três áreas do conhecimento de uma universidade pública, sendo 117 de biológicas, 138 de exatas e 177 de humanas, uma pergunta: "O que você espera de um bom professor? Justifique." Os alunos foram orientados a responder de maneira descritiva, salientando as qualidades. 
No conjunto, foram coletadas 2.332 menções, algumas lacônicas, que destacavam "espero que ele cumpra suas obrigações", como se já estivesse claramente explícito o papel do professor e não houvessem contradições entre as expectativas docente, discente e da própria instituição. Esse tipo de resposta do aluno mostra a ausência de diálogo quanto às expectativas, como realçado por Paulo Freire. Outros alunos alongavam-se em suas respostas, detalhando e justificando: as atividades de aula, as posturas docentes, aulas com a participação dos alunos, com situações simuladas, seminários; relataram expectativas quanto às situações de avaliação, tratando de experiências pessoais julgadas desagradáveis, injustas ou esclarecedores. Abordaram as interações que julgavam ser as mais adequadas para o processo de aprendizagem, as habilidades docentes, o estímulo ao desenvolvimento pessoal, as questões ligadas à carreira profissional; a postura política dos docentes, o corporativismo, a responsabilidade, o compromisso com o ensino.

Em face do conjunto das respostas foram organizadas 20 categorias, com base na similaridade das resposta. O Quadro1, a seguir, mostra as categorias e a quantidade de respostas em cada uma delas. Pode-se verificar também a porcentagem das respostas em cada categoria, obtidas através das relações entre o total de alunos respondentes (432) e o número de respostas alocadas na categoria. Como forma complementar, para facilitar a visualização dos dados, a Figura 1 destaca as diferenças porcentuais das expectativas em cada categoria.

As categorias revelam um universo bastante abrangente, que caminha da competência quanto aos conhecimentos e vai até as questões de ética profissional, passando por situações da prática do ensino. Se, por um lado, os alunos destacam em suas respostas as expectativas, nas justificativas realçam os problemas que bloqueiam a realização das expectativas. Entre as categorias destacadas tem-se: na primeira, 58,3\% dos alunos apontam a importância de domínio de conhecimentos na área. Aqui realça-se que "ele precisa ser um profundo conhecedor da matéria que ensina" e que "o professor deve ser experiente, ter grande vivência no campo profissional". Nas justificativas foram encontradas queixas que salientam: "aqui têm muito professor picareta", "tem professor que não sabe nada da matéria, se você faz uma pergunta ele fica enrolando". "O sujeito para ser professor de alguma coisa precisa saber muito, do contrário não tem como ensinar". 
Quadro 1 - Distribuição das categorias de expectativas dos alunos sobre o bom professor, quantidade de respostas em cada categoria e porcentagem de respostas por total de alunos na categoria.

\begin{tabular}{|c|c|c|}
\hline Resposta do aluno sobre o que ele espera do professor & $\begin{array}{l}\text { Quantidade } \\
\text { de respostas }\end{array}$ & $\begin{array}{r}\% \text { alunos } x \\
\text { no. } \text { respostas }\end{array}$ \\
\hline $\begin{array}{l}1 \text { Que seja uma pessoa com conhecimentos na área da } \\
\text { disciplina que ministra }\end{array}$ & 252 & 58,3 \\
\hline $\begin{array}{l}2 \text { Que perceba que faz parte de um todo no ensino } \\
\text { (sua disciplina não é a única), sua contribuição é } \\
\text { fundamental na construção dos conhecimentos e da } \\
\text { identidade profissional do aluno }\end{array}$ & 122 & 28,2 \\
\hline $\begin{array}{l}3 \text { Que tenha autoridade em sala de aula (pelo } \\
\text { conhecimento que tem e por ser professor) }\end{array}$ & 178 & 41,2 \\
\hline 4 Que valorize a sua função profissional & 151 & 34,9 \\
\hline $\begin{array}{l}5 \text { Que seja atualizado em relação aos novos } \\
\text { conhecimentos }\end{array}$ & 96 & 22,2 \\
\hline 6 Que assuma que o ato de educar é interativo & 53 & 12,3 \\
\hline $\begin{array}{l}7 \text { Que no processo educativo seja sensível aos estilos } \\
\text { de aprendizagem }\end{array}$ & 72 & 16,6 \\
\hline $\begin{array}{l}8 \text { Que defina com a classe as regras de funcionamento } \\
\text { das aulas }\end{array}$ & 157 & 36,3 \\
\hline 9 Que tenha sensibilidade para ouvir dúvidas e queixas & 171 & 39,6 \\
\hline $\begin{array}{l}10 \text { Que tenha sensibilidade para perceber o que não foi } \\
\text { entendido pelo aluno }\end{array}$ & 47 & 10,9 \\
\hline $\begin{array}{l}11 \text { Que em situações problemáticas e conflituosas } \\
\text { vividas em sala de aula, o professor seja capaz de } \\
\text { buscar saídas democráticas }\end{array}$ & 97 & 22,5 \\
\hline $\begin{array}{l}12 \text { Não fique "preso" ao conteúdo da disciplina, mas } \\
\text { saiba exemplificar }\end{array}$ & 149 & 34,5 \\
\hline $\begin{array}{l}13 \text { Tenha boa formação cultural e assim "enriqueça" as } \\
\text { aulas }\end{array}$ & 84 & 19,4 \\
\hline $\begin{array}{l}14 \text { Seja capaz de motivar o aluno que revele } \\
\text { desinteresse pela matéria }\end{array}$ & 137 & 31,7 \\
\hline $\begin{array}{l}15 \text { Que mostra importância de sua disciplina para o } \\
\text { curso e para a formação profissional }\end{array}$ & 103 & 23,8 \\
\hline $\begin{array}{l}16 \text { Que seja capaz de buscar alternativas nos conteúdos } \\
\text { da disciplina que despertem o interesse do aluno }\end{array}$ & 127 & 29,4 \\
\hline 17 Que motive o aluno para a importância da educação & 22 & 05,1 \\
\hline $\begin{array}{l}18 \text { Que seja capaz de avaliar o conhecimento } \\
\text { transmitido em suas aulas }\end{array}$ & 211 & 48,8 \\
\hline $\begin{array}{l}19 \text { Que seja capaz de verificar o desenvolvimento do } \\
\text { aluno independente do contexto de provas }\end{array}$ & 55 & 12,7 \\
\hline \multirow[t]{2}{*}{$\begin{array}{l}20 \text { Que seja capaz de estimular o desenvolvimento da } \\
\text { ética profissional e construção da cidadania }\end{array}$} & 48 & 11,1 \\
\hline & 2332 & \\
\hline
\end{tabular}


Figura 1 - Porcentagem de respostas de expectativa dos alunos sobre o docente em cada categoria

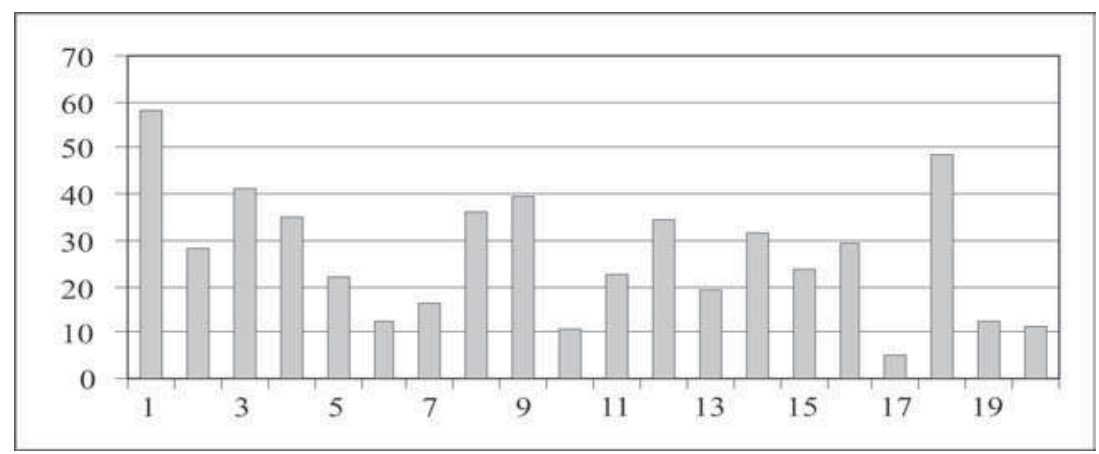

A terceira categoria também mostra relevância, pois $41,2 \%$ dos alunos esperam que o professor "tenha comando da sala", "mostre pontualidade e respeito ao aluno", "trabalhe com regras claras". Como justificativa, relatam a ocorrência de professores que não têm controle da sala, que não estabelecem um contrato de funcionamento da aula: "Cada um faz o que bem entende", "É um entra e sai da aula que só atrapalha", "tem muita conversa, e o professor não faz nada".

Na nona categoria, $39,6 \%$ dos alunos esperam que os professores mostrem sensibilidade e disponibilidade para ouvir as dúvidas e as queixas dos alunos, "quando eu não estou entendendo a matéria, espero que o professor me ajude a resolver o problema"; "não custa nada o professor perguntar: alguém não entendeu?" Os alunos criticam o fato de os professores não estabelecerem uma interação educativa com o aluno ("o professor pensa que é o dono da verdade", "se você tem uma dúvida, o professor não quer nem saber").

Na décima segunda categoria, $34,5 \%$ dos alunos têm a expectativa de que os professores não se restrinjam aos conteúdos dos textos, mas que ampliem os horizontes, dando exemplos comuns à vida profissional, fazendo ligações com outras disciplinas do curso e das atividades de estágio. Como justificativa, os alunos expressam que muitos professores simplesmente "repetem o texto", "eu acho que o professor não deve ficar lendo o que está no livro, eu sei ler muito bem, para ter aula assim prefiro ficar na biblioteca".

$\mathrm{Na}$ décima oitava categoria, $48,8 \%$ dos alunos esperam que os professores sejam "justos" na avaliação. Sem dúvida, este é um dos 
pontos polêmicos na relação ensino-aprendizagem. Há uma longa tradição na cultura avaliativa autoritária e tecnicista, e o aluno não sente que seus conhecimentos estejam sendo adequadamente avaliados. Grande parte das queixas, presentes nas justificativas, destacaram a noção de justiça. "Muitos professores nem corrigem o trabalho, dão nota pelo número de páginas"; "tem professor que cobra o que não deu"; "ele ensina muito mal e espera que gente escreva do jeito que está no livro".

Pela proximidade dos temas, algumas respostas poderiam ser alocadas em diversas categorias. Procurando reagrupá-las, dando maior sentido analítico ao estudo, verificou-se a confluência das categorias e percebeu-se que elas poderiam ser organizados em três domínios: domínio de conhecimentos, domínio de sala de aula (didático-pedagógico) e domínio da relação sociopsicológica.

A Figura 2 mostra a distribuição do número de respostas para cada um dos domínios. Para o domínio de conhecimentos foram 808 respostas, para o domínio de sala de aula, 947 e para o domínio sociopsicológico, 577.

Figura 2 - Distribuição das respostas dos alunos, no que se refere às expectativas sobre os docentes, nos domínios (1) conhecimentos, (2) sala de aula, (3) sociopsicológico

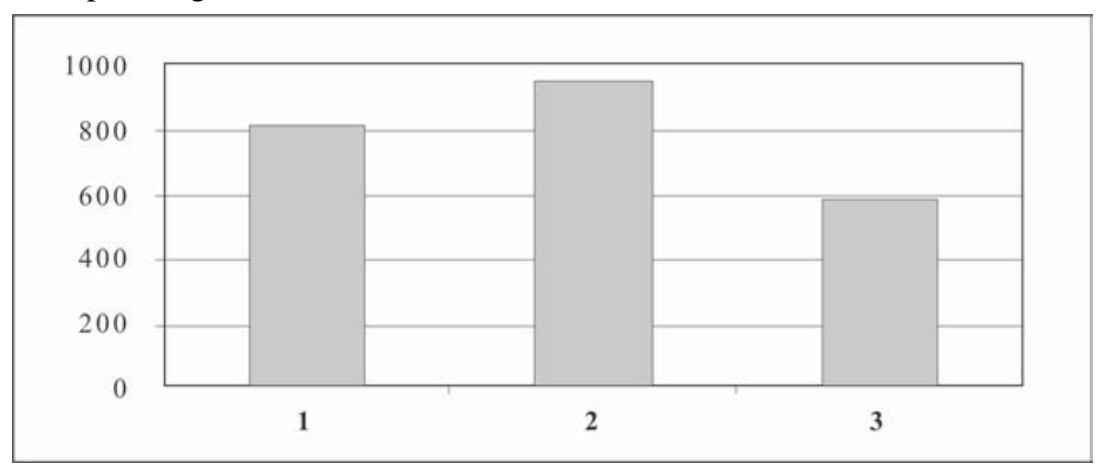

Quanto ao primeiro domínio, dos conhecimentos, foram incluídas expectativas dos alunos que revelam que o bom professor deve ter: conhecimentos no campo que pretende ensinar (categoria 1); que perceba que sua disciplina faz parte de um todo (categoria 2); que valorize a profissão (categoria 4); que passe por atualização constante (categoria 
5); que mostre a importância da sua disciplina dentro da área profissional (categoria 15); que tenha boa formação cultural (categoria 13).

Nas respostas a esse domínio, os alunos levantaram expectativas e comentaram experiências desgastantes e improdutivas baseadas na "falta de conhecimentos do professor", por não ter informações ou formação suficientes para trabalhar com a classe. Destacaram a existência de docentes improvisados, tapa-buracos, que não se envolviam com o ensino, burocratas, que, além do baixo conhecimento, eram desmotivados. Professores com formação precária, que mal demonstravam compreender a importância da disciplina que ministravam para o curso. Alguns relatos salientavam que, diante do questionamento dos alunos sobre conteúdos programáticos, o professor que não apresentava bom domínio revelava atitudes autoritárias e arrogantes.

Nas categorias que compõem o domínio de sala de aula, os alunos apontaram que o bom professor deve estabelecer as regras de funcionamento de sua disciplina com a classe, quanto a: pontualidade, formas de avaliação, relevância dos conteúdos, apresentação de trabalhos (categoria 8); deve ser capaz de avaliar os conhecimentos transmitidos (categoria 18); que não fique preso aos conteúdos do programa e mostre aplicações na vida real (categoria 12); que busque alternativas de conteúdo da disciplina para despertar o interesse dos alunos ou para superar dúvidas (categoria 16); que assuma que o ato de educar é interativo e torne as aulas dinâmicas, permitindo que o aluno participe (categoria 6); que seja sensível aos estilos de aprendizagem dos alunos (categoria 7); que tenha autoridade em sala (categoria 3).

Nesse domínio, para justificar as expectativas, os alunos fizeram queixas sobre o autoritarismo docente, citaram a falta de preparo do professor para enfrentar situações como: questionamentos, dificuldades na aprendizagem, desinteresse do aluno, cola nas avaliações, desentendimentos com os alunos, monotonia das aulas, mera repetição, "embromação", falta de compromisso do professor com o ensino.

Quanto às categorias domínio das relações sociopsicológicas, torna-se evidente que o aluno não quer encontrar no professor apenas a pessoa que lhe traga informações sobre uma área de conhecimento. Espera, em algumas situações, um modelo a seguir, um orientador que lhe indique caminhos, alguém que lhe dê apoio, como apontado por Perrenoud (2000). Os alunos esperam que o bom professor seja capaz de ouvir dúvidas e queixas (categoria 9); que seja capaz de verificar o 
desenvolvimento do aluno independentemente de provas (categoria 19); que seja capaz de superar situações conflituosas vividas em sala de aula e procure sempre saídas refletidas e democráticas (categoria 11); que motive o aluno para a importância da educação, estimule o desenvolvimento científico (categoria 17); que tenha sensibilidade para perceber o que não foi entendido pelos alunos (categoria 10); que seja capaz de motivar o aluno que revela desinteresse pela matéria (categoria 14); que seja capaz de estimular o desenvolvimento ético profissional e a construção da cidadania (categoria 20).

Esse campo apresenta uma vertente interessante: da mesma forma que se percebe a expectativa dos alunos quanto a um professor "ideal", por ser conhecedor da área profissional, solidário, incentivador e crítico, também se percebe no aluno inseguranças que revelam necessidades de amparo de um professor que funcione às vezes como modelo, afetivo e/ou profissional, para oferecer direções. O professor universitário, nesse contexto, é mais que formador de um profissional, é quem colabora na construção da identidade do aluno e também do cidadão. Estas conclusões são complementares à afirmação de Pachane (1998, p.14), citando Feldman e Newcomb:

os dados relativos à intensidade de expectativas dos estudantes indicam que estas, de modo geral, tendem a ser exageradas. Tanto as expectativas relativas à vida universitária quanto às relativas ao bom desempenho acadêmico tendem a ser maiores que as experiências vivenciadas.

Os dados obtidos a respeito da expectativa discente sobre o docente aproximam-se dos resultados colhidos por Feltran (2003 p. 99), ao destacar o conceito de sabedoria docente, quando ressalta as respostas às perguntas: "Qual foi o seu melhor professor universitário? Como ele ensinava? Como ele avaliava seus alunos? O que o distinguia dos demais?".

De outra parte, como cita Pachane (1998, p. 11), "o desencontro entre as expectativas dos alunos, que a Universidade se propõe a fazer e aquilo que realmente realiza, pode gerar no aluno uma série de decepções com sua vivência acadêmica".

A autora ressalta ser provável que a didática do professor talvez seja o centro dessas decepções.

Além disso, ao levantar expectativas, o aluno não destaca os programas de ensino, e, nesse caso, é provável que se encontre aí uma das 
grandes dificuldades do exercício docente. Os programas tendem a não corresponder ao que é esperado pelo aluno, mas o aluno não os percebe como tal, e queixa-se dos professores que, afinal, são os responsáveis pelo desenvolvimento dos programas. Isto fica evidente, como bem pode ser notado, nas categorias referentes ao domínio dos conhecimentos.

Essas considerações vão ao encontro do estudo de Snyders (1995) que indica, como "alegria das expectativas dos discentes", os sonhos acadêmicos que acabam, em grande parte, sendo frustrados.

Os dados do estudo reafirmam a posição de Freire (1995) quanto às expectativas de docentes e discentes. A distância entre elas precisa ser reduzida. Talvez deva ser vista como conteúdo de ensino, pois fomentará o debate e a reflexão. De fato, o que querem os alunos e os professores? Como chegar conjuntamente a um programa efetivo de ensino e aprendizagem que promova o desenvolvimento educacional e a formação de cidadãos? Esse é um projeto que deve ser desenvolvido no cotidiano, com a participação expressiva de docentes e discentes. Como destaca Pachane (1998, p. 14), citando Snyders (1995): “a participação configura-se como uma alegria, pois o aluno se sente ativo, importante, parte integrante de um todo maior, e não apenas um espectador".

Os dados deste estudo são relevantes, pois oferecem aos professores informações sobre as expectativas dos alunos. São úteis também às coordenações de cursos, que podem assim trabalhar para reduzir as distorções nos processos de ensino e aprendizagem. É importante ressaltar que os alunos, falando do bom professor, colocaram o foco na competência pelo domínio de conhecimentos, pela capacidade didáticopedagógica e pelo domínio nas relações sociopsicológicas.

Na medida em que o aluno em sua avaliação projeta um professor ideal, o professor, ao avaliar, imagina um aluno ideal, parece necessária a aproximação entre essas expectativas. A alternativa mais eficaz para o ajuste perceptivo é dialógica. Não só na relação comunicativa alunoprofessor, mas incluindo também o contexto institucional.

Muitos são os caminhos possíveis para promover as mudanças na educação. Um deles, que tem sido abordado e que contribui neste sentido, é partir da avaliação visando à progressão continuada, como discutido por Abramowicz (1999, p.162):

inicialmente diríamos que para implantar o regime de progressão continuada é essencial que se mude a cultura avaliativa traduzida por 
transformações na organização escolar, na sala de aula, na interação professor-aluno, nas relações com a comunidade [...] destacamos uma ressignificação para a avaliação, para o currículo, para o papel e significado do professor, da escola e da própria educação. Isso se traduz por pensar a avaliação de modo formativo, diagnóstico, contínuo, crítico, criativo, participativo.

Esse processo avaliativo, no que se refere ao professor, talvez possa contribuir para superar um "problema" identificado por Cunha (1996, p. 36) em sua pesquisa sobre o professor universitário, pois destaca que

mesmo bons professores, segundo a opinião dos alunos, trabalham na perspectiva de reprodução do conhecimento. Estes professores desenvolvem um grande número de habilidades de ensino (fazer perguntas, variar estímulos, organizar o contexto de aula etc.) e apresentam muitas qualidades humanas e afetivas no trato com o aluno e com o conteúdo de ensino. Entretanto a pesquisa mostrou que ainda não existem professores especialmente voltados para desenvolver habilidades intelectuais nos estudantes. Por exemplo, os professores são capazes de apresentar o melhor esquema do conteúdo a ser desenvolvido em aula, mas não conhecem procedimentos sobre como fazer o aluno chegar ao mapeamento próprio da aprendizagem que está realizando.

Este breve estudo procurou trazer uma visão panorâmica do que o aluno espera do professor e revela, em alguns aspectos, as características e a difícil busca do "professor necessário".

\section{ABSTRACT}

One of the various stages of institutional evaluation is the one made of the teacher by the student. When analyzing the data the institution thinks of a supposed "ideal teacher". But does the student idealize the same teacher? This study aims at investigating the expectations students have towards teachers. The main question "what do you expect from a good teacher?" was answered by four hundred and thirty-two university students. Twenty categories were applied to organize the answers in three domains: knowledge, classroom (didactics and pedagogy) and socio-psychological relation. Data shows that there is a gap between their expectations and reality.

Key Words: student's expectations, evaluation of teaching and ideal teacher. 


\section{REFERÊNCIAS}

ABRAMOWICZ, M. Avaliação e progressão continuada: subsídios para uma reflexão. In: BICUDO, M. A. V.; SILVA JUNIOR, C. A. Formação do educador e avaliação educacional. São Paulo: Editora da Unesp, 1999.

CUNHA, M. I. Ensino como pesquisa: a prática do professor universitário. Cadernos de Pesquisa. n. 97, p. 31-38, 1996.

DEMO, P. Desafios modernos da educação. Rio de Janeiro: Vozes, 2000.

DIAS, S. R. Avaliação: desafio de docentes e discentes universitários. Minas Gerais. 2000. Dissertação (Mestrado em Educação) - Unit. Centro Universitário do Triângulo.

DEPRESBITÉRIS, L. Avaliação da aprendizagem como ponto de partida para a avaliação de programas. Revista Estudos em Avaliação Educacional. Fundação Carlos Chagas, n. 15, 1997.

FELTRAN, Regina Célia S. O melhor professor universitário. VI Encontro de Pesquisa em Educação da Região Centro-Oeste. Campo Grande UCDB/UFMS, 2003.

FREIRE, P. Entrevista com Paulo Freire e Ana Maria Saul. Realizada em 2 de maio de 1995. Disponível em: www.pucsp.br/paulofreire/V\%EDdeos/Anafreir.pdf INEP. Últimas do ENC-Provão. Disponível em: www.inep.gov.br. 2003-9-19.

LUCKESI, C. C. Avaliação da aprendizagem escolar: estudos e proposições. São Paulo: Cortez, 1998.

MOREIRA, D. A. Fatores influentes na avaliação do professor: uma revisão. Revista Educação e Seleção. Fundação Carlos Chagas, n. 17. p. 73-87, 1988.

MURRAY, B.B. Monitor on Psychology. Oshkosh. EEUA, v. 31, n. 1, p. 67-73, 2000.

NOGUEIRA, M. et al. A imagem do professor no cenário educacional brasileiro. Akrópolis, Umuarama, v. 11, n. 4, p. 168-169, 2003.

OLIVEIRA, A. E. Os imaginários da avaliação. Goiânia: Universidade Católica de Goiás, 2000. (Mimeo.).

PACHANE, G. G. A universidade vivida: a experiência universitária e sua contribuição ao desenvolvimento pessoal a partir da percepção do aluno. Campinas, 1998. Dissertação (Mestrado em Educação) - Faculdade de Educação, Universidade de Campinas.

PERRENOUD, P. Avaliação: da excelência à regulação das aprendizagens. Porto Alegre: Ed. Artmed, 2000. 
SNYDERS, G. Feliz na universidade: estudo a partir de algumas biografias. Rio de Janeiro: Paz e Terra, 1995.

SOUSA, C. P. Programas de avaliação de alunos universitários. Brasília: Cátedra Unesco de Educação à Distância, UnB, 1998.

. Avaliação da aprendizagem formadora à avaliação formadora da aprendizagem. In: BICUDO, M. A. V.; SLVA JUNIOR, C. A. Formação do educador e avaliação educacional. São Paulo: Editora da Unesp, 1999. 